\title{
SCIDiC
}

\author{
International Journal of Dentistry and Oral Science (IJDOS) \\ ISSN: 2377-8075
}

\section{Preference Of Obturation Techniques used For The Treatment Of Immature Non Vital Teeth By Dental Students}

Research Article

Kalaivani Natarajan ${ }^{1}$, Mebin George Mathew ${ }^{2 *}$, Mahesh ${ }^{3}$

${ }^{1}$ Saveetha Dental College and Hospitals, Saveetha Institute of Medical and technical Sciences, Saveetha University, Chennai, India.

${ }^{2}$ Senior Lecturer, Department of Pediatric and Preventive Dentistry, Saveetha Dental College and Hospitals, Saveetha Institute of Medical and technical Sciences, Saveetha University, Chennai, India.

${ }^{3}$ Reader, Department of Pedodontics, Saveetha Dental College and Hospitals, Saveetha Institute of Medical and technical Science, Saveetha University, Chennai, India.

\section{Abstract}

Several trauma or accidents cause fracture of the front teeth. Fractures of the anterior teeth can be classified into enamel fracture, fracture involving the Dentin, involving the pulp, non vital teeth etc. In most cases, the non vital teeth are infected. Proper irrigation and obturation of the immature non vital teeth is required for successful endodontic treatment. This study aims to discuss the commonly used obturation technique by dental students for the treatment of non vital teeth. This was a university based retrospective study. Data of patients who underwent root canal treatment of the immature non vital teeth were obtained. Further sorting was done with respect to age, gender, obturation technique. Statistical analysis was done using SPSS software v20. Chi square test was done to assess the association between groups. The statistical significance was set at $5 \%$. Lateral compaction was the most preferred obturation technique with the frequency of $83.3 \%$. The most common teeth affected were the maxillary anteriors. Statistically significant association was found between the tooth involved and obturation technique $(p=0.028)$. With proper obturation technique and skills, fracture of the immature teeth can be prevented and successful treatment can be provided.

Keywords: Apexification; Apexogenesis; Lateral Compaction; Non Vital; Open Apex; Tooth Fracture.

\section{Introduction}

A non vital tooth is the one which has complete loss of blood supply, and immature teeth have incomplete root formation. Causes of immature non vital teeth may be due to trauma. Clinically there will be discoloration of the tooth associated with pain. Radiographically, there is a periapical radiolucency. When a tooth with incomplete root formation suffers pulp necrosis, the formation of dentin is stopped, root development ceases. In such a case, the canal remains large with thin and fragile walls. The root apex remains open. [1]

Endodontic treatment of such teeth has several complications. Two major difficulties involve chemco - mechanical preparation and obtaining an apical seal. The ultimate goal of endodontic treatment is the long retention of the teeth in function. Proper obturation is important for the long-term outcome. [2] Proper ob- turation involves, filling the root canal as completely as possible in order to prevent ingress of nutrients or oral microorganisms. [3] Sigurdsson et al suggest that immediate obturation of the tooth is the best timing. [4]

Proper assessment of the affected tooth is important in determining an accurate diagnosis and proper treatment planning. Frequently radiographic assessment of the affected tooth is done to assess the root development and clinical evaluation is done using the patient's history and pulp testing procedures. Apexogenesis is a procedure done to maintain the pulp vitality, which allows continued root formation along its entire length. Depending on the severity and the extent of inflammation procedures like pulp capping, shallow pulpotomy, conventional pulpotomy are done. Cvek et al explained that the affected young pulp can maintain its vitality for 7 days and only the most superficial part of the pulp has the inflammation and can be easily removed. This is because

*Corresponding Author

Dr. Mebin George Mathew,

Senior Lecturer, Department of Pediatric and Preventive Dentistry, Saveetha Dental College and Hospitals, Saveetha Institute of Medical and technical Sciences, Saveetha University,

Chennai, India.

E-mail: mebingeorgem.sdc@saveetha.com

Received: May 04, 2021

Accepted: July 09, 2021

Published: July 15, 2021

Citation: Kalaivani Natarajan, Mebin George Mathew, Mahesh. Preference Of Obturation Techniques Used For The Treatment Of Immature Non Vital Teeth By Dental Students. Int J Dentistry Oral Sci. 2021;8(7):3179-3183. doi: http://dx.doi.org/10.19070/2377-8075-21000647

Copyright: Mebin George Mathew 2021. This is an open-access article distributed under the terms of the Creative Commons Attribution License, which permits unrestricted use, distribution and reproduction in any medium, provided the original author and source are credited. 
the young dental pulp is more cellular and is able to recover from injuries.[5]

If pulp necrosis occurs, an alternative treatment approach is carried out, because of the open apex the major difficulty in immature non vital pulp is that the necrosis of the pulp causes cessation of dentin deposition in the root leaving behind a thin, fragile dentin walls that makes it difficult to clean and obtain the necessary apical seal. Traditional approaches use calcium hydroxide to induce apexification after proper disinfection of the roots. Apexification is a procedure to induce a calcified barrier in a root with an open apex or continued apical development in an incompletely formed tooth with pulpal necrosis. Completion of the endodontic treatment is typically delayed until the formation of the calcified barrier.[6] Later Mineral trioxide aggregate has become the material of choice and overcomes the disadvantages of calcium hydroxide. Studies have confirmed the clinical outcome of MTA that includes proper apical seal and healing of the existing periapical lesion in the majority of the cases. [7]

Immature non vital teeth pose special challenges during endodontic procedures because of the wide open apex and thin dentinal walls. Debridement is primarily done by chemical means to remove the pulp tissue and for disinfection. Sodium hypochlorite and calcium hydroxide have excellent tissue resolving properties and antimicrobial effects. [8] Use of antibiotics have also been reported in previous studies. [9] Previously our team has a rich experience in working on various research projects across multiple disciplines [10-24].

Thus this study was conducted to evaluate the preference of obturation technique used for the treatment of immature non vital teeth by dental students.

\section{Materials And Methods}

\section{Study setting}

This was a retrospective - university based study. The patients who underwent treatment of the immature non vital teeth are included in the study. Study duration was from June 2019 to March 2020. Ethical approval was obtained from the Institutional Ethical Committee - Saveetha Dental College. (SDC/SIHEC/2020/ DIASDATA/0619-0320). Data of patients treated with immature non vital teeth was retrospectively collected from June 2019 to March 2020. Cases with incomplete data and repeated cases were excluded from the study. The data was cross verified by another reviewer to minimise sampling bias. The age group of patients involved in our study varied from 9 years to 16 years. So, the patients in our study were grouped into 2 categories based on age. Category 1: 9 to 12 years, Category 2: 13 - 16 years. They were further sorted into 3 groups with respect to obturation technique: Category 1: lateral compaction, Category 2: matched taper single cone technique, Category 3: warm vertical compaction. The data were obtained from the patients visiting the department of Paediatric Dentistry, in our dental institution. Inclusion criteria - patients with immature non vital teeth undergoing endodontic treatment, exclusion criteria - case sheets with incomplete data. Case records were obtained from digital entries and were cross verified prior to being tabulated in Microsoft Excel sheet. Data collected was tabulated with respect to age, gender, tooth involved and obturation technique.The Excel sheet was transferred to the host computer and processed in SPSS v20. Chi square test was done to analyse the association and correlation with age and gender as independent variables and tooth involved and type of observation technique used as dependent variables. The statistical significance was set at $5 \%$.

\section{Results And Discussion}

Lateral compaction is the most preferred observation technique with a frequency of $83.3 \%$. Graph 1 represents the frequency of most preferred obturation technique for the treatment of immature non vital teeth. Lateral compaction $(83.3 \%)$ is the most preferred technique followed by warm vertical compaction and matched cone paper technique.

Graph 2 explains the association between different age groups and teeth involved. There was no statistically significant association between the age groups and teeth involved $(p=0.392)$. Graph 3 represents the association between different age groups and obturation techniques used. Lateral compaction was the only obturation technique used for children under 13 years of age, however it, was statistically not significant $(\mathrm{p}=0.086)$. Graph 4 shows association of gender and affected teeth, Males had the highest frequency of $83 \%(p=0.372)$. Graph 5 shows the association of gender and obturation technique. Lateral compaction was the commonly used technique in both males and females. The association between gender and obturation techniques was statistically not significant $(\mathrm{p}=0.424)$. Graph 6 represents the association between affected teeth and obturation technique. Lateral compaction was a commonly used technique for the maxillary anterior, followed

Graph 1: Bar graph represents the frequency of obturation technique used for the treatment of immature non vital teeth. $\mathrm{X}$ axis represents the types of obturation techniques. $\mathrm{Y}$ axis represents the number of patients. The frequency of Lateral compaction (green) was the highest with $83.33 \%$ than matched taper single cone technique (blue) with $11.1 \%$ and warm vertical compaction (red) with $5.5 \%$.

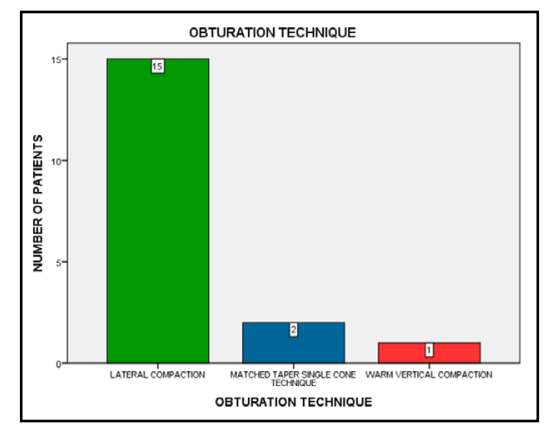


Graph 2: Bar graph shows the association between age groups and teeth involved. $\mathrm{X}$ axis represents the age groups. $\mathrm{Y}$ axis represents the number of patients. Chi square test linear by linear association p value $=0.392(>0.05)$ indicates not significant. The association between age groups and teeth involved is statistically not significant. Maxillary anteriors 11 (blue) , 21 (green) were the most commonly affected teeth.

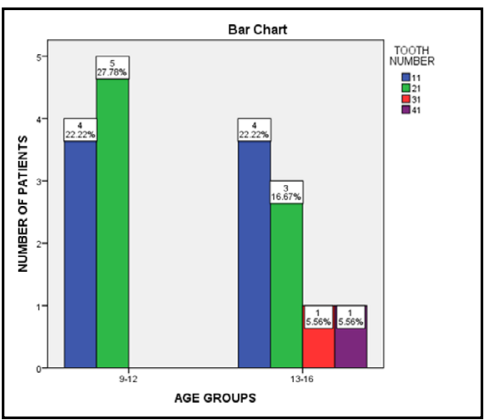

Graph 3: Bar graph shows the association of age groups and obturation technique. $X$ axis represents the age groups $Y$ axis represents the number of patients. Chi square test linear by linear association $p$ value $=0.086(>0.05)$ indicates not significant. The association between age groups and obturation technique is statistically not significant. However lateral compaction was the most commonly used obturation technique.

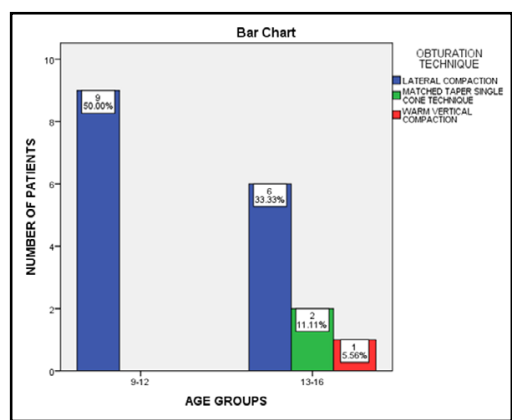

Graph 4: Bar graph shows the association between gender and teeth involved. $\mathrm{X}$ axis represents the age groups (female, male), $\mathrm{Y}$ axis represents the number of patients. Chi square test linear by linear association p value $=0.372(>0.05)$ indicates not significant. The association between gender and teeth involved is statistically not significant. However, males had higher frequency of teeth involved.

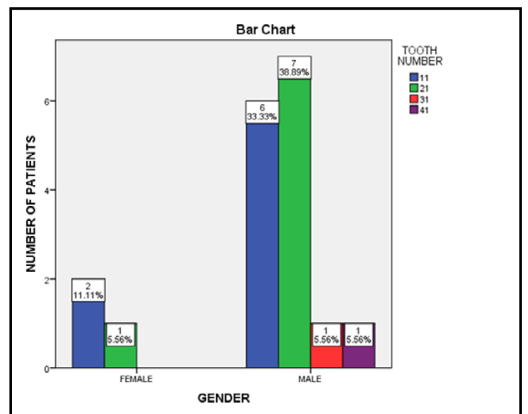

Graph 5: Bar graph shows the association between gender and obturation technique. $\mathrm{X}$ axis represents the age groups (female,male), $\mathrm{Y}$ axis represents the number of patients. Chi square test linear by linear association p value $=0.424(>0.05)$ indicates not significant. The association between gender and obturation technique is statistically significant. Lateral compaction (blue) was the frequently used obturation technique in both males and females.

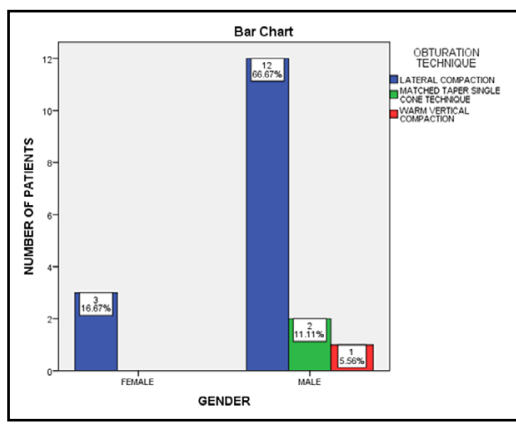

by match cone taper technique and warm vertical compaction and was statistically significant $(\mathrm{p}=0.028)$.

Root canal filling or obturation is an integral part of endodontic therapy. The purpose of obturation of the prepared root canal space is to prevent coronal leakage, bacterial contamination, seal the apex from periapical tissue fluids and the remaining irritants in the canal. Cold lateral compaction is the most commonly taught and practiced obturation technique worldwide and is set as a benchmark against other obturation techniques that has to be evaluated. This technique has several advantages that include low cost, the ability to control the length to fill. However certain disadvantages like formation of voids, spreader tracts, incomplete fusion of gutta percha and lack of adaptation leaves the treatment success questionable.[25]

In our study the frequency of most preferred obturation technique for the treatment of immature non vital teeth was assessed 
Graph 6: Bar graph shows the association between tooth involved and obturation technique. $\mathrm{X}$ axis represents the tooth involved (11,21,31,41), $\mathrm{Y}$ axis represents the number of patients. Chi square test linear by linear association p value $=0.028(<0.05)$ indicates not significant. The association between tooth involved and obturation technique is statistically not significant. Lateral compaction (blue) was the frequently used obturation technique, however they were not preferred in the mandibular anteriors.

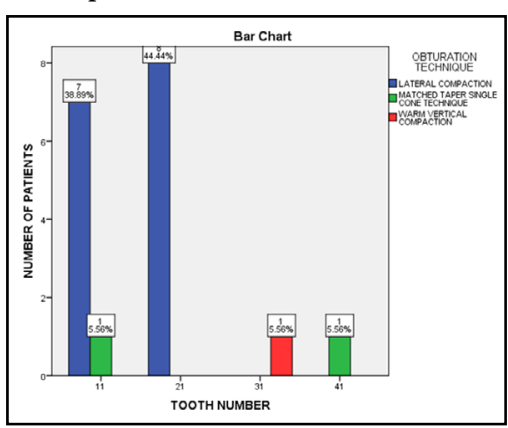

(graph 1). Lateral compaction is the most preferred technique with $83.3 \%$ followed by warm vertical compaction and matched cone taper technique. Studies have been conducted by Maryam Raoof, in which the findings are similar to the present study. The study states that the most popular obturation technique is cold lateral compaction. [26]

The association between the different age groups and teeth involved was assessed using Chi square test (Graph 2). The patients in our study were categorised into 2 equal groups 9 to 12 years and 13 to 19 years. The frequency of the tooth involved was also equal. There was no statistically significant association between the different age groups and teeth involved $(p=0.392)$

The association between different age groups and obturation techniques used was assessed using chi square test (Graph 3). Lateral compaction was the only obturation technique used for children under 13 years of age. But for patients above 13 years of age, all three techniques were used - lateral condensation, warm vertical compaction and match cone taper technique. Yet lateral compaction remains the most preferred obturation technique. However, there was no statistically significant association between age group and obturation technique $(p=0.086)$. Al.Omari et al conducted a survey on the attitudes, materials and methods employed in Endodontic treatment by General Dental Practitioners in North Jordan. The results showed $31.3 \%$ used lateral condensation technique, $9.9 \%$ used vertical compaction and $12.2 \%$ used paste. The findings were similar to our present study. [27]

The association of gender and affected teeth was assessed using Chi square test (graph 4). The female participants in our study were only about $16.67 \%$ and the involvement of mandibular anterior was only in male participants, this is due to contact sports and trauma. Kumar Reddy assessed the incidence of traumatic dental injuries in children aged 3 - 18 years in Tirupathi. The results showed that highest frequency of Traumatic Dental Injuries were between 10-12 years old, the highest cause being fall and contact sports $[28,29]$. There was no statistically significant association between the gender and tooth affected $(p=0.372)$

On assessing the association between the gender and the obturation techniques used for the treatment of immature non vital tooth with Chi square test (graph 5) we could see the lateral compaction was the only technique used for the females, whereas all three techniques were used for males. As far as research has been conducted, there is no association between gender and the choice of obturation technique. In our study this corresponds to the tooth involved. Since, mandibular teeth are involved only in the male population, all three obturation techniques are involved in the males. However no statistically significant association between the gender and obturation technique $(\mathrm{p}=0.424)$.

The association between affected teeth and obturation technique was assessed using Chi square test (graph 6). Lateral compaction was commonly used technique for the maxillary anterior $(83.3 \%)$, followed by matched cone taper technique $(11.1 \%)$ and warm vertical compaction $(5.5 \%)$ for mandibular anteriors. There was a statistically significant association between the tooth involved and obturation technique.Our institution is passionate about high quality evidence based research and has excelled in various fields [30-40].

The findings of our present study adds up to the overall consensus of the previous similar studies. Yet, the study has few limitations, the sample size is very small and hence the results cannot be generalised to a larger population. The study was conducted in a University in Chennai. Hence, the study is single centered, possible manual errors during data collection. Further studies can be done in a larger population with assessing the obturation material preferred by the students. No contradictory literature findings observed.

\section{Conclusion}

The preference of obturation techniques for the treatment of immature non vital teeth was assessed. Lateral compaction is the most preferred technique with the frequency of $83 \%$. With proper obturation technique and skills, fracture of the immature teeth can be prevented and successful treatment can be provided.

\section{Author Contributions}

First author ( Kalaivani N) performed the analysis, interpretation and wrote the manuscript. Second author (Dr.Mebin George Mathew) contributed to conception, data design, analysis, interpretation and critically reviewed the manuscript. Third author (Dr. Mahesh Ramakrishnan) participated in the study and revised the manuscript. All the three authors have discussed the results and contributed to the final manuscript.

\section{Acknowledgment}

The authors are thankful to Saveetha Dental College for provid- 
ing permission to access the database and for giving a platform to express our knowledge.

\section{References}

[1]. Iqbal Z, Qureshi AH. Monoblock obturation technique for non-vital immature permanent maxillary incisors using mineral trioxide aggregate: results from case series. J Coll Physicians Surg Pak. 2014 Jan;24(1):56-9.Pubmed PMID: 24411545.

[2]. Cvek M, Hollender L, Nord CE. Treatment of non-vital permanent incisors with calcium hydroxide. VI. A clinical, microbiological and radiological evaluation of treatment in one sitting of teeth with mature or immature root. Odontol Revy. 1976 Jan 1;27(2):93-108.

[3]. Li GH, Niu LN, Zhang W, Olsen M, De-Deus G, Eid AA, et al. Ability of new obturation materials to improve the seal of the root canal system: a review. Acta Biomater. 2014 Mar;10(3):1050-1063.Pubmed PMID: 24321349

[4]. Card SJ, Sigurdsson A, Ørstavik D, Trope M. The effectiveness of increased apical enlargement in reducing intracanal bacteria. J Endod. 2002 Nov 1;28(11):779-83.

[5]. Shabahang S. Treatment options: apexogenesis and apexification. Pediatr Dent. 2013 Apr 15;35(2):125-8.

[6]. Sheehy EC, Roberts GJ. Use of calcium hydroxide for apical barrier formation and healing in non-vital immature permanent teeth: a review. Br Dent J. 1997 Oct 11:183(7):241-6.Pubmed PMID: 9364090.

[7]. Holden DT, Schwartz SA, Kirkpatrick TC, Schindler WG. Clinical outcomes of artificial root-end barriers with mineral trioxide aggregate in teeth with immature apices. J Endod. 2008 Jul;34(7):812-7.Pubmed PMID: 18570985.

[8]. Sjögren U, Figdor D, Spångberg L, Sundqvist G. The antimicrobial effect of calcium hydroxide as a short-term intracanal dressing. nt Endod J. 1991 May;24(3):119-25

[9]. Das S. Apexification in a nonvital tooth by control of infection. J Am Dent Assoc. 1980 Jun;100(6):880-1.Pubmed PMID: 6929840.

[10]. Hafeez N. Accessory foramen in the middle cranial fossaRes. J. Pharm. Technol. 2016;9(11):1880-2.

[11]. Krishnan RP, Ramani P, Sherlin HJ, Sukumaran G, Ramasubramanian A, Jayaraj G, et al. Surgical Specimen Handover from Operation Theater to Laboratory: A Survey. Ann Maxillofac Surg. 2018 Jul-Dec;8(2):234-238. Pubmed PMID: 30693238

[12]. Somasundaram S, Ravi K, Rajapandian K, Gurunathan D. Fluoride Content of Bottled Drinking Water in Chennai, Tamilnadu. J Clin Diagn Res. 2015 Oct;9(10):ZC32-4.Pubmed PMID: 26557612.

[13]. Felicita AS. Orthodontic extrusion of Ellis Class VIII fracture of maxillary lateral incisor - The sling shot method. Saudi Dent J. 2018 Jul;30(3):265269.Pubmed PMID: 29942113

[14]. Kumar S, Rahman R. Knowledge, awareness, and practices regarding biomedical waste management among undergraduate dental students. Asian J Pharm Clin Res. 2017;10(8):341.

[15]. Gurunathan D, Shanmugaavel AK. Dental neglect among children in Chennai. J Indian Soc Pedod Prev Dent. 2016 Oct 1;34(4):364-9.

[16]. Sneha S. Knowledge and awareness regarding antibiotic prophylaxis for infective endocarditis among undergraduate dental students. Asian J Pharm Clin Res. 2016 Oct 1:154-9.

[17]. Dhinesh B, Lalvani JI, Parthasarathy M, Annamalai K. An assessment on performance, emission and combustion characteristics of single cylinder diesel engine powered by Cymbopogon flexuosus biofuel. Energy Convers Manage. 2016 Jun 1;117:466-74.

[18]. Choudhari S, Thenmozhi MS. Occurrence and Importance of Posterior Condylar Foramen. Res J Pharm Technol . 2016;8:11-43.

[19]. Paramasivam A, Vijayashree Priyadharsini J, Raghunandhakumar S. N6adenosine methylation $(\mathrm{m} 6 \mathrm{~A})$ : a promising new molecular target in hypertension and cardiovascular diseases. Hypertens Res. 2020 Feb;43(2):153154.Pubmed PMID: 31578458

[20]. Wu F, Zhu J, Li G, Wang J, Veeraraghavan VP, Krishna Mohan S, et al. Biologically synthesized green gold nanoparticles from Siberian ginseng induce growth-inhibitory effect on melanoma cells (B16). Artif Cells Nanomed Biotechnol. 2019 Dec;47(1):3297-3305.Pubmed PMID: 31379212.

[21]. Palati S, Ramani P, Shrelin HJ, Sukumaran G, Ramasubramanian A, Don
KR, et al. Knowledge, Attitude and practice survey on the perspective of oral lesions and dental health in geriatric patients residing in old age homes. Indian J Dent Res. 2020 Jan-Feb;31(1):22-25.Pubmed PMID: 32246676.

[22]. Saravanan M, Arokiyaraj S, Lakshmi T, Pugazhendhi A. Synthesis of silver nanoparticles from Phenerochaete chrysosporium (MTCC-787) and their antibacterial activity against human pathogenic bacteria. Microb Pathog. 2018 Apr;117:68-72.Pubmed PMID: 29427709.

[23]. Govindaraju L, Gurunathan D. Effectiveness of Chewable Tooth Brush in Children-A Prospective Clinical Study. J Clin Diagn Res. 2017 Mar;11(3):ZC31-ZC34.Pubmed PMID: 28511505.

[24]. Vijayakumar Jain S, Muthusekhar MR, Baig MF, Senthilnathan P, Loganathan S, Abdul Wahab PU, et al. Evaluation of Three-Dimensional Changes in Pharyngeal Airway Following Isolated Lefort One Osteotomy for the Correction of Vertical Maxillary Excess: A Prospective Study. J Maxillofac Oral Surg. 2019 Mar;18(1):139-146.Pubmed PMID: 30728705.

[25]. Ansari BB, Umer F, Khan FR. A clinical trial of cold lateral compaction with Obtura II technique in root canal obturation. J Conserv Dent. 2012 Apr;15(2):156-60

[26]. Raoof M, Zeini N, Haghani J, Sadr S, Mohammadalizadeh S. Preferred materials and methods employed for endodontic treatment by Iranian general practitioners. Iran Endod J. 2015;10(2):112-6.Pubmed PMID: 25834595.

[27]. Al-Omari WM. Survey of attitudes, materials and methods employed in endodontic treatment by general dental practitioners in North Jordan. BMC Oral Health. 2004 Sep 10;4(1):1.Pubmed PMID: 15361258

[28]. Reddy KV, Kumar KN, Venkatasubramanian R, Togaru H, Kannakiah S, Reddy R. Incidence of traumatic dental injuries in children aged 3-18 years in Tirupathi. Int. J. Pedod. Rehabil. 2017 Jul 1;2(2):73.

[29]. Trope M. Treatment of the immature tooth with a non-vital pulp and apical periodontitis. Dent Clin North Am. 2010 Apr 1;54(2):313-24.

[30]. Vijayashree Priyadharsini J. In silico validation of the non-antibiotic drugs acetaminophen and ibuprofen as antibacterial agents against red complex pathogens. J Periodontol. 2019 Dec;90(12):1441-1448.Pubmed PMID: 31257588.

[31]. Pc J, Marimuthu T, Devadoss P, Kumar SM. Prevalence and measurement of anterior loop of the mandibular canal using CBCT: A cross sectional study. Clin Implant Dent Relat Res . 2018 Apr 6;20(4):531-4.

[32]. Ramesh A, Varghese S, Jayakumar ND, Malaiappan S. Comparative estimation of sulfiredoxin levels between chronic periodontitis and healthy patients - A case-control study. J Periodontol. 2018 Oct;89(10):1241-1248.Pubmed PMID: 30044495 .

[33]. Ramadurai N, Gurunathan D, Samuel AV, Subramanian E, Rodrigues SJ. Effectiveness of $2 \%$ Articaine as an anesthetic agent in children: randomized controlled trial. Clin Oral Investig. 2019 Sep;23(9):3543-50.

[34]. Sridharan G, Ramani P, Patankar S, Vijayaraghavan R. Evaluation of salivary metabolomics in oral leukoplakia and oral squamous cell carcinoma. J Oral Pathol Med. 2019 Apr;48(4):299-306.

[35]. Ezhilarasan D, Apoorva VS, Ashok Vardhan N. Syzygium cumini extract induced reactive oxygen species-mediated apoptosis in human oral squamous carcinoma cells. J Oral Pathol Med. 2019 Feb;48(2):115-121.Pubmed PMID: 30451321

[36]. Mathew MG, Samuel SR, Soni AJ, Roopa KB. Evaluation of adhesion of Streptococcus mutans, plaque accumulation on zirconia and stainless steel crowns, and surrounding gingival inflammation in primary molars: randomized controlled trial. Clin Oral Investig. 2020 Sep;24(9):1-6.Pubmed PMID: 31955271

[37]. Samuel SR. Can 5-year-olds sensibly self-report the impact of developmental enamel defects on their quality of life? Int J Paediatr Dent. 2021 Mar;31(2):285-286.Pubmed PMID: 32416620.

[38]. R H, Ramani P, Ramanathan A, R JM, S G, Ramasubramanian A, et al. CYP2 C9 polymorphism among patients with oral squamous cell carcinoma and its role in altering the metabolism of benzo[a]pyrene. Oral Surg Oral Med Oral Pathol Oral Radiol. 2020 Sep;130(3):306-312.Pubmed PMID: 32773350 .

[39]. Chandrasekar R, Chandrasekhar S, Sundari KKS, Ravi P. Development and validation of a formula for objective assessment of cervical vertebral bone age. Prog Orthod. 2020 Oct 12;21(1):38.Pubmed PMID: 33043408

[40]. Vijayashree Priyadharsini J, Smiline Girija AS, Paramasivam A. In silico analysis of virulence genes in an emerging dental pathogen A. baumannii and related species. Arch Oral Biol. 2018 Oct;94:93-98.Pubmed PMID: 30015217. 